\title{
Follicular Epithelial Dysplasia as Hashimoto Thyroiditis-Related Atypia: a Series of 91 Specimens
}

\author{
Ivana Kholová ${ }^{1,2}$ (1) David Kalfert ${ }^{3} \cdot$ Jarkko Lintusaari $^{1,2} \cdot$ Erja Rajakorpi $^{4} \cdot$ Marie Ludvíková $^{5}$
}

Accepted: 5 May 2021 / Published online: 15 May 2021

(c) The Author(s) 2021

\begin{abstract}
Follicular epithelial dysplasia (FED) is described as Hashimoto thyroiditis-related atypia and is thought to be a possible precancerous lesion. Dysplasia as an interface between normal state and carcinoma is described in a wide range of diseases and carcinogenesis chains. On the other hand, inflammation-related atypia and cancerogenesis is also widely studied. In this study, we retrospectively analyzed 91 specimens of thyroid gland surgical resections with FED during a 10-year-period at the university hospital pathology department. The study population consisted of 68 females and 15 males aged between 22 and 86 years. The preoperative cytology diagnoses had mainly been in the indeterminate categories with prevailing AUS/FLUS results in the FED-only group $(\mathrm{p}=0.005)$ and suspicious for malignancy and malignant in the group with FED plus adjacent malignancy. The decision for surgery was malignancy related in $48.2 \%$ of the cases. The lesions were sized $0.1-3.5 \mathrm{~mm}$ and multifocal in $45.1 \%$ of the cases. Immunohistochemically, the atypical cells were cyclin D1-positive in $67.5 \%$, galectin-3 in $72.7 \%$, CK19 in $85.7 \%$, and HBME-1 in $87.0 \%$ of cases. In conclusion, FED is suggested to be a pathogenetic link between inflammation-related atypia and papillary carcinoma and thus a premalignant precursor of papillary carcinoma in HT as $36.1 \%$ of the specimens contained also papillary carcinoma in the present study. Both histopathological nuclear features and the immunoprofile of FED are widely shared with that of papillary carcinoma.
\end{abstract}

Keywords Follicular epithelial dysplasia $\cdot$ Hashimoto thyroiditis $\cdot$ Papillary thyroid carcinoma $\cdot$ Inflammation $\cdot$ Fine-needle aspiration $\cdot$ Cytohistologic discrepancy

\section{Introduction}

Hashimoto thyroiditis (HT) known also as chronic lymphocytic thyroiditis is an autoimmune disease microscopically featuring diffuse lymphoplasmacytic inflammation with lymphoid follicles containing germinal centres, follicular

Ivana Kholová

ivana.kholova@tuni.fi

1 Fimlab Laboratories, Tampere, Finland

2 Faculty of Medicine and Health Technology, Tampere University, Tampere, Finland

3 Department of Otorhinolaryngology and Head and Neck Surgery, First Faculty of Medicine, University Hospital Motol, Charles University, Prague, Czech Republic

4 Pathology Department, Seinäjoki Central Hospital, Seinäjoki, Finland

5 Department of Biology, Faculty of Medicine in Pilsen, Charles University, Pilsen, Czech Republic epithelial damage, epithelial atrophy, oncocytic and rarely squamous metaplasia and fibrosis [1].

A close relation of inflammation and cancer was noticed in many studies. Already in 1863, the father of modern pathology Rudolf Virchow suggested a link between inflammation and cancer observing inflammatory cells in neoplastic tissue $[2,3]$. Moreover, the inflammation belongs to the enablers of malignancy and is involved in the pathogenesis of cancer as it was introduced by Hanahan and Weinberg in 2011 [4]. Tumor-promotion inflammation makes possible the acquisition of functional capabilities called hallmarks of cancer by supplying bioactive molecules to the tumor microenvironment. These molecules are responsible for cell growth, resisting cell death, inducing angiogenesis etc. [5]. Tumor-associated inflammatory cells such as dendritic cells, mast cells, macrophages, T-lymphocytes, regulatory $\mathrm{T}$ cells, and natural killer cells are observed in many tumors including thyroid carcinomas [2, 6]. The association of HT with thyroid cancer, namely, thyroid papillary carcinoma, is reported with variable frequency up to $38 \%[2,6]$. The 
pathogenetic mechanism is nevertheless under debate with at least the following possibilities: tumor immune-escape mechanism, inflammatory immune response to preexisting autoimmunity and cross-reacting antitumor immunity [7].

Inflammatory bowel disease-related chronic inflammation is well recognized as a risk factor for colorectal cancer development with epithelial changes including a variety of inflammation-induced hyperplasia to dysplasia as well [8]. Dysplasia, that is disordered growth, is characterized by both cellular and architectural changes at the interface between normal state and carcinoma, being described in a wide range of tissues and organs [9].

In parallel, HT is characterized by epithelial changes [1], and variable atypia related to HT has been observed [10-14]. The elegant paper by Chui et al. used the term of follicular epithelial dysplasia (FED) in the thyroid gland with HT for the first time [15]. The FED lesions were described as groups of atypical cells with a diameter less than $1.0 \mathrm{~cm}$ with mild to moderate nuclear enlargement, membrane irregularities, chromatin margination, grooves, and crowding of nuclei with optical clearings variably present. Architecturally, the foci are irregularly shaped forming follicles, trabeculae, nests, and solid areas, but no papillae. Those groups are distinct from surrounding epithelium as well as from papillary microcarcinoma by lacking infiltrative growth and stromal desmoplasia [15].

In the present study, we analyzed morphological, immunohistochemical, and clinical characteristics of FED in HT specimens collected in a tertiary care university centre during a 10 -year period.

\section{Materials and Methods}

The archives and consultation files of the Pathology Department, Fimlab Laboratories, Tampere, Finland, were searched for HT cases with atypia fulfilling the histopathological criteria of FED. The epidemiological, laboratory, histopathological, and immunohistochemical features of these cases were analyzed.

Immunohistochemical staining was done on $2-\mu \mathrm{m}$-thick sections with Ventana Life Sciences Benchmark XT@ Staining module (Ventana Medical Systems, Inc., Tucson, Arizona (AZ), USA) using antibodies against cytokeratin 19 (CK19) (clone A53-B/A2.26; Ventana Medical Systems, Inc., Tucson, AZ, USA), galectin-3 (clone 9c4; Ventana Medical Systems, Inc., Tucson, AZ, USA), cyclin D1 (clone SP4, Ventana Medical Systems, Inc., Tucson, AZ, USA) and Hector Battifora mesothelial-1 (HBME-1) (clone HBME1; Ventana Medical Systems, Inc., Tucson, AZ, USA). The FED lesion was assessed as positive if $>10 \%$ of cells were positive in agreement with a previous study [15].
All statistical analyses were performed using IBM SPSS statistics (version 22.0; SPSS, IBM, Armonk, NY, USA). The data were analyzed using Fisher's exact test (twotailed), Pearson's chi-square test and Mann-Whitney U test. $P$-values $<0.05$ were considered statistically significant in all statistical analyses.

\section{Results}

The study cohort consisted of 91 samples from 83 patients operated on within a 10-year-period (2010-2019). In addition to Fimlab Laboratories archival cases, there were 5 consultation cases from regional pathology laboratories. There were 68 females and 15 males with the average age of $54.5 \pm 10.8$ years (ranged from 22 to 86 years). The specimens were total thyroidectomies in 37 (44.6\%) cases and lobectomies in the rest of the cases. The reasons for surgery were clinical or fine-needle aspiration (FNA) diagnosed malignancy or suspicion, including lobectomies after malignancy in a contralateral lobe $(n=44$ cases, $48.2 \%)$, goiterrelated symptoms $(n=43,47.4 \%)$, hyperthyroidism $(n=2$, $2.2 \%)$ and hyperparathyroidism $(\mathrm{n}=2,2.2 \%)$. The average amount of blocks/specimen was 16 (range 6-55). In case of malignancy, the specimen was entirely blocked.

In addition to HT, histopathological diagnoses consisted of malignant neoplasms $(\mathrm{n}=38(45.8 \%)$, including papillary carcinoma $(n=30$, microcarcinoma in 13 cases), follicular carcinoma $(n=6)$, medullary carcinoma $(n=1)$, and anaplastic carcinoma $(n=1))$. Benign neoplasms $(n=9(10.8 \%))$ were all follicular adenomas. There were 2 cases with multiple tumors: one with a follicular carcinoma and a papillary microcarcinoma and the other with a papillary microcarcinoma and a follicular adenoma. The neoplastic cases are summarized in Table 1. There were 14 immunoglobulin G4 (IgG4)-positive HT cases (16.9\%) [16], but there has not been shown any relationship between FED and IgG4 positivity.

In $53(63.9 \%)$ cases, there was a preceding FNA taken. The cytopathological diagnoses according to the Bethesda System for Reporting Thyroid Cytopathology (TBSRTC) $[17,18]$ are summarized in Table 2 . Strikingly, in both the malignant and the benign groups, the majority of cases $(n=20)$ were placed into the indeterminate categories. Even in the FED-only group, 8 cases (32\%) were diagnosed as suspicious for malignancy or malignant. In the atypia of undetermined significance/follicular lesion of undetermined significance (AUS/FLUS) category, there were significantly more FED-only cases (12 vs. 3, $p=0.005$ ).

Morphologically, the lesions were characterized as groups of follicular epithelial cells with a variable degree of atypia including nuclear enlargement, nuclear membrane irregularities, nuclear optical clearing, chromatin margination, nuclear 
Table 1 The summary of neoplasms, their subtypes and cases with multiple neoplasms in FED cases

\begin{tabular}{|c|c|c|c|c|c|}
\hline \multirow{2}{*}{$\begin{array}{l}\text { Neoplasms }(\mathrm{n}=47,56.6 \%) \\
\text { Histological type }\end{array}$} & \multicolumn{4}{|c|}{ Malignant neoplasms $(\mathrm{n}=38,45.8 \%)$} & \multirow{2}{*}{$\begin{array}{l}\begin{array}{l}\text { Benign neoplasms } \\
(\mathrm{n}=9,10.8 \%)\end{array} \\
\text { Follicular adenoma }\end{array}$} \\
\hline & Papillary carcinoma & Follicular carcinoma & $\begin{array}{l}\text { Medullary } \\
\text { carcinoma }\end{array}$ & $\begin{array}{l}\text { Anaplastic } \\
\text { carcinoma }\end{array}$ & \\
\hline $\mathrm{n}$ & 30 & 6 & 1 & 1 & 9 \\
\hline Histological subtype & Papillary microcarcinoma & ND & ND & ND & ND \\
\hline $\mathrm{n}$ & 13 & ND & ND & ND & ND \\
\hline Case 1 with 2 neoplasms & 1 papillary microcarcinoma & 1 follicular carcinoma & - & - & - \\
\hline Case 2 with 2 neoplasms & 1 papillary microcarcinoma & - & - & - & 1 follicular adenom \\
\hline
\end{tabular}

grooves, and crowding of nuclei. There were mainly irregularly shaped follicles and to a lesser extent trabeculae, nests, and sparsely solid areas without any formation of papillae on the architectural level. No infiltrative growth or adjacent stromal desmoplasia were found. Geographically, the FED foci were observed within the inflammatory infiltrate with no proximity to the concomitant tumor if present (Fig. 1).

On average, the size of the FED focus was $0.59 \pm 0.05 \mathrm{~mm}$ ranging from 0.1 to $3.5 \mathrm{~mm}$. In specimens with one focus only, the size was $0.72 \pm 0.05 \mathrm{~mm}$ with a range of $0.1-3.5 \mathrm{~mm}$. The measure was smaller $0.46 \pm 0.02$ with a range of $0.1-1.2 \mathrm{~mm}$ in cases with 2 focuses. In specimens with 3 focuses, the range was $0.1-2.2 \mathrm{~mm}$ with an average $0.86 \pm 0.03 \mathrm{~mm}$. In the only case with 4 focuses, the range of the focuses was $0.1-0.2 \mathrm{~mm}$ and an average of $0.125 \pm 0.01 \mathrm{~mm}$. The FED sizes were not significantly different between the groups .

The multiple FED foci were associated with the diagnosis of HT only in 17 patients and with the combined HT and neoplasia (19 carcinomas and 5 adenomas) in 24 patients. One (1.1\%) case of non-neoplastic FED four foci were revealed. Three foci were detected in $8(8.8 \%)$ cases including both papillary and follicular carcinoma cases. There were 2 foci in a total of $32(35.2 \%)$ cases. One focus

Table 2 The summary of TBSRTC categories in preoperative FNA samples according to final pathological anatomical diagnosis (PAD)

\begin{tabular}{lll}
\hline SD (Bethesda categories) & PAD & \\
\cline { 2 - 3 } & FED & $\begin{array}{l}\text { FED and } \\
\text { carcinoma }\end{array}$ \\
\hline Insufficient & 2 & 1 \\
Benign & 2 & 2 \\
AUS/FLUS & 12 & 3 \\
Follicular neoplasm & 1 & 2 \\
Suspicious for malignancy & 7 & 15 \\
Malignant & 1 & 5 \\
Total & 25 & 28 \\
\hline
\end{tabular}

only was found in 50 (54.9\%) cases consisting of 25 nonneoplastic HT cases and 21 HT with carcinoma cases and 4 HT with adenoma cases. There was no statistical correlation between FED multifocality or FED topography and accompanying neoplastic pathology.

Immunohistochemical profiles were studied by markers previously found to be related to thyroid malignancy such as CK19, galectin-3, HBME-1, and cyclin D1 [15, 19-22]. Due to the size of the lesions, there were 14 (15.4\%) cases with undetectable residual FED lesion in the IHC slides. The immunohistochemical results are summarized in Table 3. Statistically, cyclin D1 positivity was significantly higher in FED cases with papillary carcinoma than in FED without neoplasia $(p=0.018)$, also in all malignant tumors in comparison to FED without neoplasia $(p=0.008)$. Furthermore, galectin- 3 positivity correlated with the size of the FED lesions $(p=0.002$ in unifocal cases and $p<0.001$ in multifocal cases) (Fig. 2).

No statistical correlation was detected between laboratory data (TSH, T4, T3, TPO antibodies, TSH antibodies) preoperatively or postoperatively and FED size or immunohistochemistry.

\section{Discussion}

In the present study, we described FED features in 91 thyroid gland specimens from 83 patients diagnosed with thyroid pathology in the university pathology department during a 10-year-period including epidemiological, preoperative clinical and cytological, laboratory, morphological, and immunohistochemical characterization of patients and lesions. There was a female predominance of disease, and $45.8 \%$ of cases contained concomitant malignancy. Preoperative cytological diagnoses were indeterminate in the majority of cases. The lesions had cellular and architectural atypia with focal features of papillary carcinoma. They were located inside the inflammatory areas. The lesions were sized $0.1-3.5 \mathrm{~mm}$ and often multifocal with up to 4 focuses in $45.1 \%$ of the samples. 
Fig. 1 The examples of microscopic features of FED. a Two irregular follicles with crowded nuclei embedded in lymphocytic infiltrate (haematoxylin and eosin staining, $100 \times$ original magnification). b Irregularly shaped follicles with crowded nuclei in the area of lymphocytic infiltrate (haematoxylin and eosin staining, $100 \times$ original magnification). c Detail of irregular groups of epithelial cells with oncocytic cytoplasmatic change, loss of nuclear roundness and with nuclear enlargement and few nuclear grooves (haematoxylin and eosin staining, $200 \times$ original magnification). d Irregularly shaped follicle with crowded hyperchromatic nuclei (haematoxylin and eosin staining, $200 \times$ original magnification)
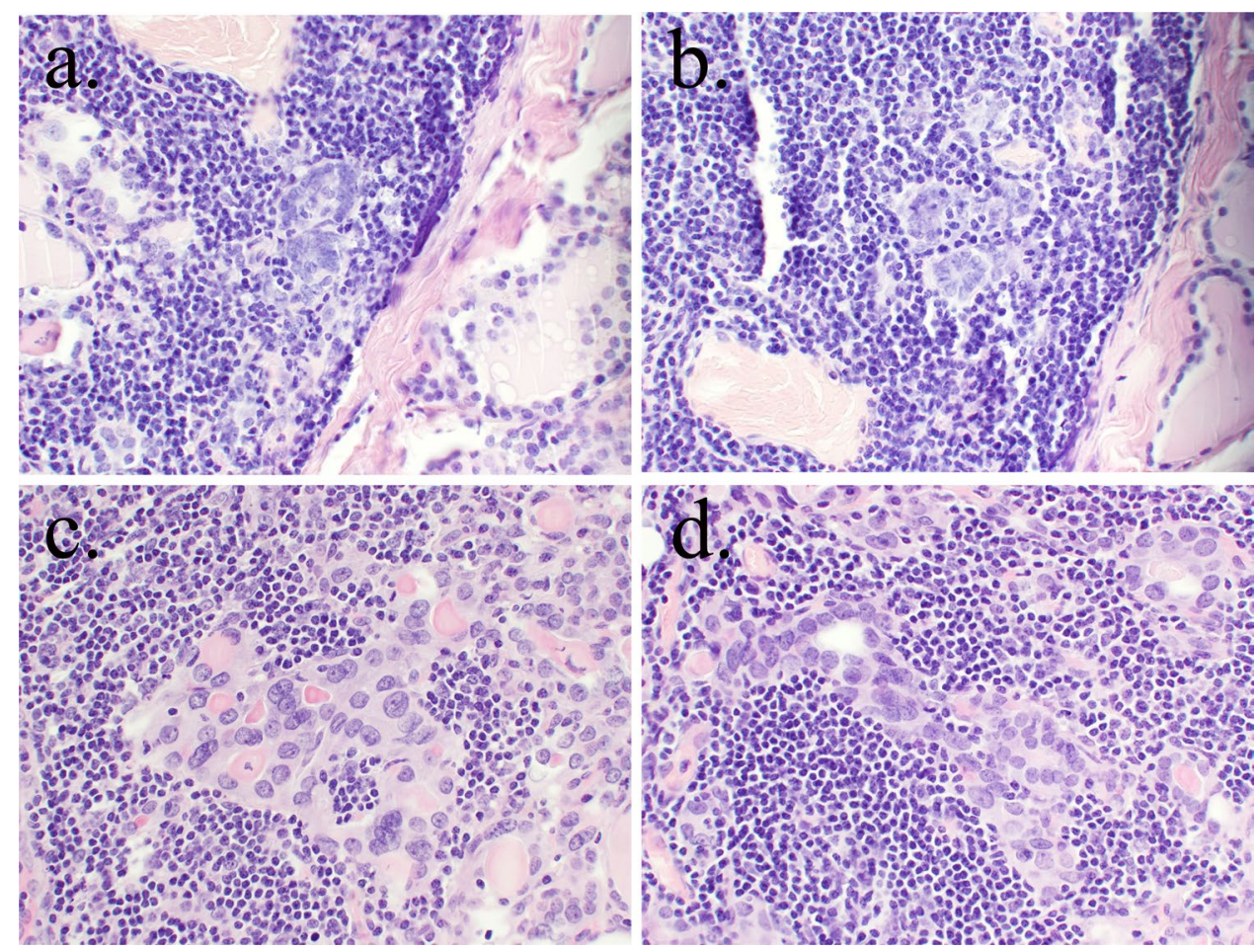

Histopathological changes like optically clear nuclei, prominent cytoplasmic invaginations with intranuclear cytoplasmic inclusions, and occasional nuclear grooves were observed in the follicular epithelium in HT by Berho and Suster already in 1995 [11]. The observation was repeated by others $[10,12-14]$ with the latest study by Chui et al. [15] naming the lesions as FED that we also use and favour. Chui et al. collected 124 cases with detailed immunohistochemical analysis in 50 out of them [15]. In the majority of the studies, there were less than 100 cases collected [12, $14,23,24]$.

In our series, cyclin D1 was positive in $67.5 \%$, galectin-3 in $72.7 \%$, CK19 in $85.7 \%$, and HBME-1 in $87.0 \%$ of the FED foci. Cyclin D1 positivity was significantly associated both with FED cases with papillary carcinoma and with any kind of malignancy compared to FED only. In addition, galectin-3 positivity correlated with the size of FED lesion. In the literature, c-met was shown in $66 \%$ of the FED cases in the addition to galectin-3, cyclin D1 and HBME-1 positivity in a proportion of the FED lesions [13]. In another study in the follicular epithelial cells with papillary carcinoma-like nuclear features in HT, galectin-3, CK19, and HBME-1 were strongly and diffusely positive in $17-87 \%$ of the cases [24]. On the contrary, all 12 cases were positive for HBME- 1 and CK19, but BRAF-negative in a series by Nasr et al. [14]. CK19 was shown to be statistically significantly increased in the FED foci in comparison to peritumoral normal benign thyroid tissue [23]. Papillary carcinoma-associated protein expression in HT may rise the possibility of later activation of cancerogenesis in HT [24]. Rhoden et al. showed RET rearrangement in non-neoplastic cells in HT pointing out the common molecular mechanisms in early cancer development and inflammation [25]. In summary, FED lesions share most of the immunoprofile with papillary carcinoma.

Weetman summarized the mechanisms of follicular cell injury in HT as cytokine, complement, and exocytosis activation, loss of tight junction, and Fas and Fas ligand upregulation [26]. It was hypothesized that the atypia is a

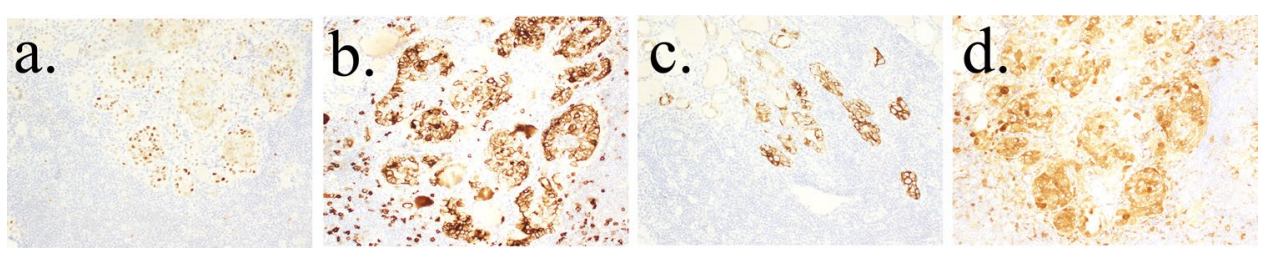

Fig. 2 Immunohistochemical positivity in FED lesions: a cyclin D1 (200×original magnification), b HBME-1 (200× original magnification), c CK19 (200 $\times$ original magnification), d galectin-3 ( $200 \times$ original magnification) 
Table 3 The results of immunohistochemical analysis

\begin{tabular}{llll}
\hline Immunostaining & $\begin{array}{l}\text { Positive (n,\% of } \\
\text { evaluated cases) }\end{array}$ & $\begin{array}{l}\text { Negative (n,\% of } \\
\text { evaluated cases) }\end{array}$ & N.D. \\
\hline Cyclin D & $52(67.5 \%)$ & $25(32.5 \%)$ & 14 \\
HBME-1 & $67(87.0 \%)$ & $10(13.0 \%)$ & 14 \\
CK19 & $66(85.7 \%)$ & $11(14.3 \%)$ & 14 \\
Galectin-3 & $56(72.7 \%)$ & $21(27.3 \%)$ & 14 \\
\hline
\end{tabular}

regenerative hyperplasia reacting to basement membrane abnormalities [12], but morphologically, those changes are more dysplastic than hyperplastic [9]. Papillary carcinomarelated proteins were not expressed in HT-related hyperplasia or metaplasia [24]. Significantly higher Ki-67 positivity $(p<0.001)$ supports dysplastic change [12]. An important paper by Asioli et al. showed a morphological relation of solid cell nests to papillary microcarcinoma in HT cases. Nuclear clearing and grooves were common in the nests, but the immunoprofile was different [27].

Dysplasia as a starting point in a carcinogenesis chain is described in a wide range of diseases with textbook examples of inflammatory bowel disease-related chronic inflammation as a risk factor for colorectal carcinoma development $[8,9]$. Dysplasia is characterized by cellular and architectural changes forming a confluence between normal tissue and carcinoma [9].

In larger series and epidemiological studies, HT is often linked to malignancy. The association of HT with thyroid papillary carcinoma was reported with the frequency up to $38 \%$ [2, 6]. Despite the epidemiological link between HT and papillary carcinoma, the immunologic linkage is under discussion: is papillary carcinoma development as immuneescape mechanism or a target-specific immune response? Is HT development a cross-reacting antitumor immunity? [7] In HT, immunologic tolerance towards the thyroid tissue is lost [1]. The immune reaction is characterized by the increase in pro-inflammatory cells and cytokines and the decrease in anti-inflammatory cytokines levels. Thyroglobulin and TPO are the main immunological target in HT and analogically also in the immune response in papillary carcinoma [7].

The present study supports the concept of immune-escape mechanisms and target-specific immune responses, but further cell level studies are warranted. FED can thus be proposed as a precursor lesion of papillary carcinoma as suggested previously [15, 23].

Based on our and literature findings, follow-up of cases where only lobectomy was performed is warranted, and even lobectomy performance may be advisable. We see a parallel with dysplasia in other organs and tissues dysplasia that are followed up clinically.

In our series, the reason for surgical intervention was a malignancy diagnosed clinically, cytologically, or in a contralateral lobe in $48.2 \%$ of cases. In the surgical resection specimens, the thyroid gland contained concomitant malignancy in $45.8 \%$ of cases with papillary carcinoma in $36.1 \%$ of cases and benign neoplasm in $10.8 \%$. In the series of Nasr et al., $42 \%$ of the cases contained papillary microcarcinoma and FED foci [14].

In the preoperative diagnostics of thyroid nodules, FNA has a central role [28]. The interpretation of nuclear atypia can be challenging. As seen in our study, 8 cases with FED only were misinterpreted as malignant or suspicious for malignancy. Another 12 cases were grouped in TBSRTC AUS/FLUS category.

FED is a challenge both in histology and cytology samples with the danger of both overdiagnosis as papillary carcinoma and underdiagnosis $[29,30]$. In the literature, follicular epithelial atypia related to HT was described as a possible pitfall in cytological diagnostics [23, 29] in agreement with our observations. Powdery chromatin, occasional nuclear grooves and holes, and paucity of background lymphocytes were shown to be the main features leading to overdiagnosis of papillary carcinoma in the HT cases [30]. Despite of being a diagnostic hallmark, the nuclear grooves were observed also in benign hyperplastic nodules and follicular adenomas originally falsely positively diagnosed in FNA [31]. There is a need for the experience and expertise of thyroid pathologists and cytopathologists, consultations, and second opinions in problematic cases. The TBSRTC AUS/FLUS category is reserved for lesions with uncertain and focal features of malignancy [17, 18, 32, 33], and consultations may help to reduce false positivity in FED-like cases.

\section{Conclusions}

In conclusions, FED is suggested to be a pathogenetic link between inflammation-related atypia and papillary carcinoma and thus a precursor of papillary carcinoma in HT as suggested by the fact that $36.1 \%$ of the FED containing specimens contained concomitant papillary carcinoma in the present study. In agreement, both the histopathological features and the immunoprofile of FED are widely shared with papillary carcinoma.

In the FNA of thyroid nodules, HT-related atypia can lead to indeterminate diagnoses, namely, the TBSRTC AUS/ FLUS category. The research of us and others supports FED as a diagnostic entity and its adding into the international terminology and guidelines.

Acknowledgements The administrative support of Suvi Hovi and Emma Pakkanen is acknowledged. The participation in thyroid diagnostics routine by Lasse Nieminen and Riikka Salonen is acknowledged. 
Author Contribution Conceptualization: I.K.; M.L., Methodology: I.K., D.K., J.L.; Validation: D.K., J.L.; Formal analysis: I.K., D.K., J.L.; Investigation: I.K., D.K., J.L., E.R., M.L.; Resources: I.K.; Data curation: I.K., D.K., J.L., E.R.; Writing—original draft preparation: I.K.; Writing—review and editing: I.K., D.K., J.L., E.R., M.L.; Visualization: I.K., D.K.; Supervision: I.K., M.L.; Project administration: I.K.; Funding acquisition: I.K.

Funding This research was funded by VTR-grant from Pirkanmaa Hospital District and Pirkanmaa Cancer Foundation (both to I.K), the Charles University Research Fund (Progres Q28/LF1 (UNCE 204013)) (to D.K.), the Charles University Research Fund (Progres Q39) (to M.L.).

\section{Declarations}

Ethics Approval All procedures were performed in the accordance with the ethical standards of the Ethical Committee of Pirkanmaa Hospital District and with the Helsinki declaration (1975, revised 1983). After the approval by the Ethical Committee (R13168), informed consent of each individual was not requested. The use of tissue blocks was approved by the National Supervisory Authority for Welfare and Health (Valvira).

Research Involving Human and Animal Participants Additional declarations for articles in life science journals that report the results of studies involving humans and/or animals.

Conflict of Interest The authors declare no competing interests.

Open Access This article is licensed under a Creative Commons Attribution 4.0 International License, which permits use, sharing, adaptation, distribution and reproduction in any medium or format, as long as you give appropriate credit to the original author(s) and the source, provide a link to the Creative Commons licence, and indicate if changes were made. The images or other third party material in this article are included in the article's Creative Commons licence, unless indicated otherwise in a credit line to the material. If material is not included in the article's Creative Commons licence and your intended use is not permitted by statutory regulation or exceeds the permitted use, you will need to obtain permission directly from the copyright holder. To view a copy of this licence, visit http://creativecommons.org/licenses/by/4.0/.

\section{References}

1. Nikiforov YE, Biddinger PW, Thompson LDR (2020) Chronic Lymphocytic Thyroiditis (Hashimoto or Autoimmune Thyroiditis). In: Nikiforov YE, Biddinger PW, Thompson LDR (eds) Diagnostic Pathology and Molecular Genetics of the Thyroid: A Comprehensive Guide for Practicing Thyroid Pathology. Wolters Kluwer N.V., Alphen aan den Rijn, the Netherlands, pp 60-71

2. Pusztaszeri MP, Faquin WC, Sadow PM (2014) Tumor-Associated Inflammatory Cells in Thyroid Carcinomas. Surg Pathol Clin 7 (4):501-514. https://doi.org/10.1016/j.path.2014.08.006

3. Galdiero MR, Varricchi G, Marone G (2016) The immune network in thyroid cancer. Oncoimmunology 5 (6):e1168556. https:// doi.org/10.1080/2162402X.2016.1168556

4. Hanahan D, Weinberg RA (2011) Hallmarks of cancer: the next generation. Cell 144 (5):646-674.https://doi.org/10.1016/j.cell. 2011.02.013

5. DeNardo DG, Andreu P, Coussens LM (2010) Interactions between lymphocytes and myeloid cells regulate pro- versus anti-tumor immunity. Cancer Metastasis Rev 29 (2):309-316.https://doi.org/10.1007/s10555-010-9223-6

6. Guarino V, Castellone MD, Avilla E, Melillo RM (2010) Thyroid cancer and inflammation. Mol Cell Endocrinol 321 (1):94-102. https://doi.org/10.1016/j.mce.2009.10.003

7. Ehlers M, Schott M (2014) Hashimoto's thyroiditis and papillary thyroid cancer: are they immunologically linked? Trends Endocrinol Metab 25 (12):656-664. https://doi.org/10.1016/j.tem.2014. 09.001

8. Matkowskyj KA, Chen ZE, Rao MS, Yang GY (2013) Dysplastic lesions in inflammatory bowel disease: molecular pathogenesis to morphology. Arch Pathol Lab Med 137 (3):338-350.https://doi. org/10.5858/arpa.2012-0086-RA

9. Kumar V, Abbas AK, Aster JC (2020) Neoplasia. In: Kumar V, Abbas AK, Aster JC (eds) Robbins \& Cotran Pathologic Basis of Disease. Elsevier Health Sciences, Philadelphia, USA, pp 267-338

10. Arif S, Blanes A, Diaz-Cano SJ (2002) Hashimoto's thyroiditis shares features with early papillary thyroid carcinoma. Histopathology 41 (4):357-362. https://doi.org/10.1046/j.1365-2559. 2002.01467.x

11. Berho M, Suster S (1995) Clear nuclear changes in Hashimoto's thyroiditis. A clinicopathologic study of 12 cases. Ann Clin Lab Sci 25 (6):513-521

12. Doganay L, Puyan FO, Oz F, Ergul Z, Bilgi S, Ekuklu G (2005) Regenerative hyperplasia of follicular epithelium in chronic lymphocytic thyroiditis. Appl Immunohistochem Mol Morphol 13 (4):353-357

13. Gasbarri A, Sciacchitano S, Marasco A, Papotti M, Di Napoli A, Marzullo A, Yushkov P, Ruco L, Bartolazzi A (2004) Detection and molecular characterisation of thyroid cancer precursor lesions in a specific subset of Hashimoto's thyroiditis. Br J Cancer 91 (6):1096-1104.https://doi.org/10.1038/sj.bjc.6602097

14. Nasr MR, Mukhopadhyay S, Zhang S, Katzenstein AL (2009) Absence of the BRAF mutation in HBME1+ and CK19+ atypical cell clusters in Hashimoto thyroiditis: supportive evidence against preneoplastic change. Am J Clin Pathol 132 (6):906-912.https:// doi.org/10.1309/AJCPCGCZZ1OYF0IC

15. Chui MH, Cassol CA, Asa SL, Mete O (2013) Follicular epithelial dysplasia of the thyroid: morphological and immunohistochemical characterization of a putative preneoplastic lesion to papillary thyroid carcinoma in chronic lymphocytic thyroiditis. Virchows Arch 462 (5):557-563.https://doi.org/10.1007/s00428-013-1397-1

16. Lintusaari J, Vesaniemi E, Kalfert D, Ilvesaro J, Ludvikova M, Kholova I (2020) IgG4-positive plasma cells in Hashimoto thyroiditis: IgG4-related disease or inflammation-related IgG4positivity? APMIS 128 (9):531-538. https://doi.org/10.1111/apm. 13067

17. Ali SZ, Cibas ES (2010) The Bethesda System for Reporting Thyroid Cytopathology: Definitions, Criteria and Explanatory Notes. 1 st edn. Springer, New York, USA

18. Ali SZ, Cibas ES (2018) The Bethesda System for Reporting Thyroid Cytopathology. 2nd edn. Springer, Cham, Switzerland

19. Cochand-Priollet B, Dahan H, Laloi-Michelin M, Polivka M, Saada M, Herman P, Guillausseau PJ, Hamzi L, Pote N, Sarfati E, Wassef M, Combe H, Raulic-Raimond D, Chedin P, Medeau V, Casanova D, Kania R (2011) Immunocytochemistry with cytokeratin 19 and anti-human mesothelial cell antibody (HBME1) increases the diagnostic accuracy of thyroid fine-needle aspirations: preliminary report of 150 liquid-based fine-needle aspirations with histological control. Thyroid 21 (10):1067-1073. https://doi.org/10.1089/thy. 2011.0014

20. Fadda G, Rossi ED, Raffaelli M, Pontecorvi A, Sioletic S, Morassi F, Lombardi CP, Zannoni GF, Rindi G (2011) Follicular thyroid neoplasms can be classified as low- and high-risk according to HBME-1 and Galectin-3 expression on liquid-based fine-needle 
cytology. Eur J Endocrinol 165 (3):447-453. https://doi.org/10. 1530/EJE-11-0181

21. Margari N, Giovannopoulos I, Pouliakis A, Mastorakis E, Gouloumi AR, Panayiotides IG, Karakitsos P (2018) Application of Immunocytochemistry on Cell Block Sections for the Investigation of Thyroid Lesions. Acta Cytol 62 (2):137-144.https://doi.org/10.1159/ 000485824

22. Kalfert D, Ludvikova M, Kholova I, Ludvik J, Topolocan O, Plzak J (2020) Combined use of galectin-3 and thyroid peroxidase improves the differential diagnosis of thyroid tumors. Neoplasma 67 (1):164-170. https://doi.org/10.4149/neo_2019_190128N86

23. Ma H, Yan J, Zhang C, Qin S, Qin L, Liu L, Wang X, Li N (2014) Expression of papillary thyroid carcinoma-associated molecular markers and their significance in follicular epithelial dysplasia with papillary thyroid carcinoma-like nuclear alterations in Hashimoto's thyroiditis. Int J Clin Exp Pathol 7 (11):7999-8007

24. Prasad ML, Huang Y, Pellegata NS, de la Chapelle A, Kloos RT (2004) Hashimoto's thyroiditis with papillary thyroid carcinoma (PTC)-like nuclear alterations express molecular markers of PTC. Histopathology 45 (1):39-46. https://doi.org/10.1111/j.1365-2559. 2004.01876.x

25. Rhoden KJ, Unger K, Salvatore G, Yilmaz Y, Vovk V, Chiappetta G, Qumsiyeh MB, Rothstein JL, Fusco A, Santoro M, Zitzelsberger H, Tallini G (2006). RET/papillary thyroid cancer rearrangement in nonneoplastic thyrocytes: follicular cells of Hashimoto's thyroiditis share low-level recombination events with a subset of papillary carcinoma. J Clin Endocrinol Metab. 91 (6):2414-23. https://doi.org/10.1210/jc.2006-0240.

26. Weetman AP (2004) Cellular immune responses in autoimmune thyroid disease. Clin Endocrinol (Oxf) 61 (4):405-413.https://doi. org/10.1111/j.1365-2265.2004.02085.x

27. Asioli S, Erickson LA, Lloyd RV (2009). Solid cell nests in Hashimoto's thyroiditis sharing features with papillary thyroid microcarcinoma. Endocr Pathol. 20 (4):197-203. https://doi.org/ 10.1007/s12022-009-9095-x.

28. Kholová I, Schalin-Jäntti C (2018) Thyroid fine needle aspiration cytology. In: Huhtaniemi I, Martini L (eds) Encyclopedia of Endocrine Diseases, vol 4. 2nd edn. Elsevier, Amsterdam, Netherlands, pp 565-572

29. Mete O, Asa SL (2012) Pitfalls in the diagnosis of follicular epithelial proliferations of the thyroid. Adv Anat Pathol 19 (6):363373. https://doi.org/10.1097/PAP.0b013e318271a5ac

30. Mete O, Asa SL (2010) Oncocytes, oxyphils, Hurthle, and Askanazy cells: morphological and molecular features of oncocytic thyroid nodules. Endocr Pathol 21 (1):16-24.https://doi.org/ 10.1007/s12022-009-9102-2

31. Harvey AM, Truong LD, Mody DR (2012) Diagnostic pitfalls of Hashimoto's/lymphocytic thyroiditis on fine-needle aspirations and strategies to avoid overdiagnosis. Acta Cytol 56 (4):352-360. https://doi.org/10.1159/000338738

32. Jing X, Michael CW (2012) Potential pitfalls for false suspicion of papillary thyroid carcinoma: a cytohistologic review of 22 cases. Diagn Cytopathol 40 Suppl 1:E74-79.https://doi.org/10.1002/dc. 21726

33. Kholova I, Ludvikova M (2014) Thyroid atypia of undetermined significance or follicular lesion of undetermined significance: an indispensable Bethesda 2010 diagnostic category or waste garbage? Acta Cytol 58 (4):319-329. https://doi.org/10.1159/000366498

Publisher's Note Springer Nature remains neutral with regard to jurisdictional claims in published maps and institutional affiliations. 